\title{
EDITORIAL Open Access Publishing in Medicine
}

\author{
A Saw, FRCS (Ed), KH Ng*, PhD \\ Department of Orthopaedic Surgery, University Malaya Medical Centre, Kuala Lumpur, Malaysia \\ *Department of Biomedical Imaging, University Malaya Medical Centre, Kuala Lumpur, Malaysia
}

\section{INTRODUCTION}

Traditionally, most medical journals are financially dependant of subscriptions from individual readers, research groups, libraries and academic institutions. Clinicians and public health administrators used to obtain up to date literature from libraries that subscribe to these journals. However, with the increasing use of internet, dissemination of news and information online has taken over much of the roles of the libraries. In addition, awareness of the need to make output of publicly funded research freely available has challenged the traditional remuneration where publishers source financial returns through subscriptions.

"Open Science" was introduced to highlight the need for research outputs to be made available without restriction or delay ${ }^{1}$. Making selected or all the content of a journal available online is a form of open science. Open access (OA) is a form of open science where a journal policy allows articles to be read, duplicated and distributed without fees as long as recognition is made to the contributors.

Despite what appeared to be a simple description, the actual definition of OA remains controversial. Funding of the publisher is mostly transferred to the authors in the form of article processing charges (APCs). In many circumstances, APCs are absorbed by research grants. Contribution of authors and original source are usually attributed according to the Creative Commons Attribution License that is used. The concept of OA is not new. British Medical Journal (BMJ) has adopted open access approach since 1990s, and by 1998 all research articles of BMJ are available without charge $^{2}$.

Electronic journal that is available online is not equivalent to OA journal. Some electronic journals provide restricted access to members of organizations, while others will charge fees for access and downloading of their articles. Although hosting of electronic journals still require considerable cost in terms of processing, editing and uploading the materials online, the overall expense is much lower compared to printing and circulating hardcopy journals. Page limitation of hardcopy journals is one of the factors contributing towards low acceptance rate for publication. In many established journals, it is not uncommon for articles with sound scientific values being rejected due to page constrain. As an example, acceptance rate of eleven traditional journals published by the American Heart Association (AHA) is as low as $10 \%{ }^{3}$

Another adverse consequence is long delay in the publication of accepted articles. In some instances, the waiting period may be one year or longer. For these reasons, electronic publication can be expected to dominate future medical literature although not all of them will adopt OA approach. Examples of two OA journals based in this country is Biomedical Intervention and Imaging Journal (BIIJ) that publishes only in electronic form (www.biij.org) and Malaysian Orthopaedic Journal (MOJ) that publishes in both hardcopy and electronic form (www.morthoj.org). Electronic journals that adopt OA will facilitate progress in medical services and research outputs in developing regions like Asia and South America where resources for literature search are limited. Pressure from the academia for promotional purpose and funding bodies for research products as the basis to continue their financial support further contributes towards flourishing of new OA journals.

\section{Types of open access journals}

There are many ways a journal allows its content to be shared online without charges or subscription. They can be broadly classified into the following groups ${ }^{4}$ :

1. Free access journal:

These journals are usually funded by commercial firm and the content may not undergo peer review process. Scientific value of the articles is generally limited but they can be easily accessed through internet search engines or emails communications.

2. Gold open access journal:

Funding by Gold OA journals usually comes from APC, and most authors will claim the payment from their institutions or research funds. All the articles are available for immediate and unlimited downloading through the internet without any charges. 
3. Green open access journal:

Green open access generally refers to the arrangements of allowing published articles to be made available for immediate and unlimited downloading. Pubmed Central (PMC) is one of the early pioneers that serve as repository for authors to make their articles accessible to the public.

4. Delayed open access journal:

Some journals allow their articles to be made available following a period of carefully decided embargo period. Period of embargo for science, technology and medicine (STM) journals can be less than twelve months, while those in the field of social science may be up to several years to ensure minimal effect to the original pool of subscribers.

\section{Features of $\mathrm{OA}$ publishing:}

By allowing free and unlimited access to published materials, OA journals provide researchers with the opportunity to perform comprehensive literature review through the internet. Medical OA journals allow a clinician to look for relevant information on the condition that they are managing. Critical peer review can be performed more effectively when most of the resources and literature are available online. Researchers will be able to perform literature review in order to prepare high quality discussions based on their study outcome. Eventually, expenses in the form of APC will most likely be absorbed by the institutions or funding agencies. In general, medical and health professions will benefit from the whole OA system, and only those involved in clinical and basic science research will have to contribute financially for their research output to be published. Although some studies have shown that currently most researchers still do not consider OA as a main criterion when they select a journal to publish their articles ${ }^{5}$, we can expect the scenario to change in the very near future.

\section{Areas of concern}

With the flourishing of OA journals, there has been a noticeable decline in the standard of published material ${ }^{6}$. Authors are now the main contributor to the income for the journal. Publishing more articles will translate into higher income for the publisher, and the risk of compromise in scientific standard cannot be ignored ${ }^{7}$. Reducing the period of peer review and editing process may also be associated with lowering of scientific standard and increasing ethical problems like falsification, duplication, and plagiarism ${ }^{8}$.
Due to the effectiveness of internet communication, increasingly more editing processes are being assigned to technical staff with no or limited medical knowledge. Some journals maintain a big pool of peer reviewers but limit the role of editors in the running of routine publication. As an example, Hindawi Publishing Corporation publishes more than 400 titles including Case Reports in Medicine. OA journals published by Hindawi do not have editors-in-chief, and most of the editing work is performed by secretariat staff ${ }^{9}$. Although nearly all medical journals clearly state that authors will be responsible for accuracy and scientific value of published material, there are many tasks that require someone with medical experience who are familiar with editorial work to uphold editorial freedom and be responsible for various tasks as stated in the International Committee of Medical Journal Editors (ICMJE) recommendations ${ }^{10}$

Some journals make use of the Gold OA model to achieve financial gain through APCs contributed by authors or funding agencies. Poor quality papers will be accepted for publication despite negative comments from reviewers. These so called "predatory" journals will solicit submissions through email contacts, offer rapid reviewing and high rate of acceptance. There is very limited or no information on the editorial board members. There is also no traceable office address, and there no national or regional affiliation to the publisher $^{11}$.

\section{Summary}

OA method of publishing is here to stay, although the actual transition from traditional subscription based publication would probably take many more years to achieve. There are still many unresolved problems in relation to various aspects of OA journals, as it is still the early phase of evolution. In developing countries, Gold OA journals that do not require APC would be the ideal solution for clinicians and researchers with limited financial resources. The journal will have to be sponsored by professional bodies or advertisements. This model will allow the journal publisher to maintain high scientific and ethical standards of published material while allowing immediate and free access to all the readers. 


\section{REFERENCES}

1. David P. The Historical Origins of "Open Science" http://www-siepr.stanford.edu/workp/swp06008.pdf. Accessed 2014 Feb 16

2. Homepage of British Medical Journal. http://www.bmj.com/archive. Accessed 16th February 2014

3. Goodell H. One Society’s Perspective on Open Access Publishing. Science editor 2013; 36(1): 16.

4. Homepage of Biomedical Imaging and Intervention Journal. http;//www.biij.org/ Accessed on 16th February 2014

5. Homepage of Malaysian Orthopaedic Journal. http://www.morthj.org/ Accessed on 16th February 2014

6. Conway M. Open access Demystified: Flavors, colors, and practices in today's Scholarly Publishing Marketplace. Science editor 2013; 36(1): 3-4.

7. Crotty D. Open access: Scholarly Publishers Can Take the Lead. Science Editor 2013; 36(1): 5-7.

8. Beall J. Predatory publishers threaten to erode scholarly communication. Science Editor 2013; 36(1): 18-9.

9. Poynder R. The OA Interviews. Ahmad Hindawi. http://poynder.blogspot.com/2012/09/the-oa-interviewes-ahmed-hindawifounder.html. Accessed on 16th February 2014

10. CSE's White Paper on Promoting Integrity in Scientific Journal Publications. http://www.councilscienceeditors.org/i4a/pages/ index.cfm?pageid 3636\#216. Accessed on 16th February 2014

11. Beall J. Predatory publishers are corrupting open access Nature 2012: 489; 179. 